\title{
Reticulocyte Corpuscular Hemoglobin Concentration Mean
}

National Cancer Institute

\section{Source}

National Cancer Institute. Reticulocyte Corpuscular Hemoglobin Concentration Mean.

NCI Thesaurus. Code C138970.

An indirect measurement of the average concentration of hemoglobin per reticulocyte in a biological specimen, calculated as the ratio of hemoglobin to hematocrit. 